\title{
Potensi Pariwisata Garut Dalam Mewujudkan Ekonomi Kreatif
}

\author{
Tetep, Ade Suherman, Eldi Mulyana, Triani Widyanti, Wanti Pebriani, Yuyun Susanti, Ilah \\ Institut Pendidikan Indonesia \\ Jl. Terusan Pahlawan No.32, RW.01, Sukagalih, Kec. Tarogong Kidul, Kabupaten Garut, Jawa Barat 44151
}

\begin{abstract}
Abstrak - Penelitian ini bertujuan untuk mengetahui potensi pariwisata garut dalam mewujudkan ekonomi kreatif. Metode yang digunakan dalam penelitian ini kualitatif yang bersifat deskriptif, proses dan makna lebih di tonjolkan dalam penelitian kualitatif. Landasan teori dimanfaatkan sebagai pemandu agar fokus peneliti sesuai dengan fakta di lapangan untuk mengkaji secara sungguhsungguh tentang teori-teori dan konsep-konsep yang berkaitan dengan topik yang akan diteliti. Objek yang diteliti yaitu salah satu daerah tujuan wisata di Kabupaten Garut Cipanas, Situ Bagendit, Candi Cangkuang, Pantai Santolo merupakan tujuan wisata yang sering kali dikunjungi oleh wisatawan. Hasil penelitian ditemukan bahwa salah satu cara untuk meningkatkan tingkat kunjungan wisatawan mancanegara adalah dengan membangun dan memperbaiki sarana prasarana pariwisata yang sudah ada melalui inovasi dengan mengkombinasi unsur budaya dengan sarana prasarana pariwisata yang sudah ada atau belum terbangun. Dengan kombinasi sarana prasarana dengan unsur budaya lokal akan tercipta keunikan yang khas pada sarana prasarana pariwisata di Jawa Barat dengan demikian tingkat kunjungan wisatawan mancanegara akan meningkat serta unsur budaya tidak akan hilang atau tergerus oleh budaya asing yang dibawa oleh wisatawan asing yang datang di Jawa Barat dan pada akhirnya akan meningkatkan tingkat kunjungan wisata di Indonesia pada umumnya. Garut merupakan salah satu wilayah yang sangat lengkap, mulai dari pariwisata pantai, pariwisata petualangan, pariwisata pegunungan, dan pariwisata artificial dapat di jadikan sebagai sumber pendapatan asli daerah (PAD) dari sektor pariwisata yang sangat menjanjikan. Kabupaten Garut merupakan salah satu daerah tujuan wisata di Jawa Barat karena banyak memiliki potensi wisata yang dapat menarik wisatawan untuk datang berkunjung. Banyaknya tempat objek wisata Garut seperti Cipanas, Situ Bagendit, Candi Cangkuang, Pantai Santolo merupakan tujuan wisata yang sering kali dikunjungi oleh wisatawan. Maka diperlukannya mengkaji potensi pariwisata di Kabupaten Garut untuk mewujudkan ekonomi kreatif.
\end{abstract} Kata Kunci: Parawisata, ekonomi Kreatif.

Abstract- This study aims to determine the potential of arrowroot tourism in realizing the creative economy. The method used in this research is qualitative descriptive, the process and meaning are highlighted in qualitative research. The theoretical basis is used as a guide so that the focus of the researcher is in accordance with the facts in the field to seriously study the theories and concepts related to the topic to be studied. The object under study is one of the tourist destinations in Garut Cipanas, Situ Bagendit, Cangkuang Temple, Santolo Beach, which are frequently visited by tourists. The results showed that one way to increase the level of foreign tourist visits is to build and improve existing tourism infrastructure through innovation by combining cultural elements with existing or unbuilt tourism infrastructure. With the combination of infrastructure and local cultural elements, it will create a unique uniqueness of tourism infrastructure in West Java, thus the level of foreign tourist visits will increase and cultural elements will not be lost or eroded by foreign culture brought by foreign tourists who come to West Java and in the end, it will increase the level of tourist visits in Indonesia in general. Garut is one of the most complete areas, starting from coastal tourism, adventure tourism, mountain tourism, and artificial tourism which can be used as a source of local revenue (PAD) from the very promising tourism sector. Garut Regency is one of the tourist destinations in West Java because it has a lot of tourism potential that can attract tourists to come to visit. The number of tourist attractions in Garut such as Cipanas, Situ Bagendit, Cangkuang Temple, Santolo Beach is a tourist destination that is often visited by tourists. So it is necessary to study the potential of tourism in Garut Regency to realize the creative economy.

Keywords: Tourism, Creative economy.

\section{PENDAHULUAN}

Ekonomi Kreatif merupakan sebuah konsep di era ekonomi baru yang berasal dari pemanfaatan kreativitas, keterampilan serta bakat individu untuk meningkatkan kesejahteraan serta lapangan pekerjaan yang akan menghasilkan dan mengeksploitasi daya kreasi manusia [1]. Para pakar ekonomi menyebutnya dengan istilah ekonomi kreatif, yakni sebuah talenta baru yang mengubah kehidupan masyarakat melalui ide atau gagasan kreatif, sehingga menghasilkan produk-produk bernilai tambah ekonomi yang mampu menjadikan kehidupan lebih sejahtera. Sektor pariwisata baru-baru ini menjadi bidang yang potensial untuk memberikan sumbangsih pada pertumbuhan ekonomi suatu daerah. Pariwisata sebagai sebuah industri yang sangat berpotensi dan bergantung pada keberadaan manusia untuk mewujudkan ekonomi kreatif [2]-[4]. Pariwisata bisa menjadi salah satu potensi yang dapat mewujudkan ekonomi kreatif dengan interaksi antara konsumen atau wisatawan dengan produsen atau menawarkan produk dan jasa wisata[5]. 
Pariwisata tergolong dalam ekonomi kreatif di mana melalui proses kreatif nilai tambah dihasilkan. Salah satu daerah di Jawa Barat yang memiliki potensi pariwisata adalah Kabupaten Garut. Garut merupakan salah satu daerah di Indonesia yang menjadikan pariwisata sebagai komoditas unggulan daerah yang potensial. Garut memiliki industri pariwisata yang menunjukkan konstruksi budaya, sejarah dan alam yang kompleks, sehingga melalui proses branding tujuan wisata dapat membantu menciptakan dan memasarkan citra yang unik di pasar[6]. Bagaimana daerah menjadi tempat yang inspiratif, sehingga masyarakat memiliki semangat, kecerdasan, imajinasi, dan kreativitas untuk mengembangkan ekonomi daerahnya. Implikasinya, setiap pemerintahan daerah harus mengeksplorasi kreativitas agar mampu mengelola, menumbuhkembangkan, dan meningkatkan daya saing daerahnya[7]. Dan potensi apa yang dapat diciptakan dari Kabupaten Garut itu adalah dengan pariwisata yang dimiliki daerah Garut untuk mewujudkan ekonomi kreatif. Garut merupakan salah satu wilayah yang sangat lengkap, mulai dari pariwisata pantai, pariwisata petualangan, pariwisata pegunungan, dan pariwisata artificial dapat di jadikan sebagai sumber pendapatan asli daerah (PAD) dari sektor pariwisata yang sangat menjanjikan[8].

Oleh karena itu, penulis perlu mengkaji lebih dalam lagi mengenai potensi pariwisata yang ada di wilayah Kabupaten Garut untuk mewujudkan ekonomi kreatif daerah. Penulis mengunakan metode penelitian kualitatif dimana penelitian kualitatif ini merupakan penelitian yang bersifat deskriptif dan cenderung menggunakan analisis. Untuk mengetahui Kabupaten Garut ini memiliki banyak pariwisata yang dapat dikunjungi oleh wisatawan, sehingga pariwisata merupakan salah satu potensi terbesar yang dimiliki oleh daerah Garut untuk memajukan ekonomi daerah dan mewujudkan ekonomi kreatif.

\section{KAJIAN PUSTAKA}

Pariwisata tergolong dalam ekonomi kreatif di mana melalui proses kreatif nilai tambah dihasilkan. Pariwisata sebagai kumpulann fenomena dan hubungan yang tumbuh dari interaksi antara wisatawan (para pelancong), para pengusaha dengan pemerintah dan masyarakat tuan rumah Kata Pariwisata berasal dari bahasa jawa kuna, menurut kamus besar Bahasa Indonesia: Kata pari berarti semua, segala, sekitar, sekeliling. Kata wisata berarti bepergian bersamasama untuk memperluas pengetahuan, bersenang senang dan sebagainya [9]. Pendapatan asli daerah merupakan sumber utama penerimaan bagi daerah dalam rangka pelaksanaan dasantralisasi, dana perimbangah, pinjaman daerah, dan penerimaan lai merupakan sumber pendapatan tambahan untuk mendukung PAD. Berbagai cara dilakukan Pemerintah Daerah Kabupaten dan Kota untuk meningkatkan pendapatan daerahnya dalam upaya memenuhi kebutuhan belanja pemerintah daerah bagi pelaksanaan kegiatannya. Pertama, Pemerintah Daerah Kabupaten dan Kota dapat memperoleh dana dari sumber-sumber yang dikategorikan Pendapatan Asli Daerah (PAD). salah satunya dari pendapatan pariwisata yang masuk untuk pendapatan asli daerah[10].

Langkah-langkah yang perlu dilaksanakan oleh pemerintah dalam pembenahan terhadap infrastruktur dan faktor-faktor pendukung pertumbuhan ekonomi kreatif. Dalam perspektif manajemen, diperlukan langkah strategis berupa pembinaan, perumusan regulasi/kebijakan yang lebih implementatif, pengalokasian anggaran dalam APBN maupun APBD, penguatan kapasitas usaha dan pola pendampingannya, monitoring dan evaluasi disertai pembangunan sistem dan basis datanya. Pembenahan ini akan mendukung penciptaan iklim ekonomi kreatif yang telah dimotori oleh masyarakat, sehingga menjadi lebih kondusif dan produktif. Dinas pariwisata adalah suatu bidang untuk mempromosikan wisata bahari dan lainya yang yang ada di daerah tersebut terutama di bidang pemasaran untuk menarik wisatawan lokal maupun wisata manca negara. Sarana Sarana Pariwisata adalah segala sesuatu yang melengkapi dan bertujuan untuk memudahkan proses kegiatan pariwisata dapat berjalan lancar [11] [13].

Ekonomi kreatif merupakan sistem transaksi yang memiliki pengertian lebih luas daripada industri kreatif. Ekonomi kreatif dalam perspektif penyelenggaraan pemerintahan daerah idealnya dibangun dari ide-ide inovatif yang mampu menstimulasi pertumbuhan ekonomi, bisnis, dan investasi, berorientasi daya saing menuju transformasi industri kreatif, dan dapat meningkatkan kesejahteraan masyarakat[14]. Kota yang kreatif berarti kota dimana pemerintah maupun masyarakat memiliki ide-ide kreatif serta didukung oleh kebijakan publik yang aspiratif untuk pengembangan potensi dan daya saing daerah. Pertumbuhan ekonomi suatu wilayah sangat ditentukan oleh tingkat produktivitas dan keberadaan orang-orang kreatif yang memiliki talenta khusus dengan kemampuan mengaplikasikan ilmu pengetahuan untuk menciptakan suatu inovasi[15], [16]. Ekonomi Kreatif merupakan aktivitas 
perekonomian yang lebih mengandalkan ide atau gagasan (kreatif) untuk mengelola material yang bersumber dari lingkungan di sekitarnya menjadi bernilai tambah ekonomi[3]. Terdapat 6 (enam) argumentasi perlunya pengembangan industri kreatif di Indonesia, yakni[17]-[19]:

1. Dari sisi "Kontribusi Ekonomi", menciptakan lapangan kerja, meningkatkan produk domestik bruto (PDB), dan ekspor.

2. Dari sisi "Iklim Bisnis", menciptakan lapangan usaha, dampak bagi sektor lain, dan pemasaran

3. Dari sisi "Citra dan Identitas Bangsa", meningkatkan turisme, ikon nasional, membangun budaya, warisan budaya, dan nilai lokal.

4. Dari sisi "Sumberdaya Terbarukan", berbasis pengetahuan, kreativitas, dan membangun komunitas hijau.

5. Dari sisi "Inovasi dan Kreativitas", memberikan ide, gagasan, dan penciptaan nilai.

6. Dari sisi "Dampak Sosial", meningkatkan kualitas hidup, pemerataan kesejahteraan, dan peningkatan toleransi sosial.

Dalam perkembangannya akan memberikan kontribusi ekonomi yang signifikan, menciptakan iklim bisnis yang positif, membangun citra dan identitas bangsa. Selain itu, sumberdaya dapat selalu terbarukan yang berbasis pengetahuan, kreativitas dan komunitas hijau, menuju keunggulan kompetitif bangsa berdampak sosial positif[20], [21].

\section{METODE PENELITIAN}

Penelitian ini menggunakan penelitian kualitatif dimana penelitian kualitatif ini merupakan penelitian yang bersifat deskriptif dan cenderung menggunakan analisis. Proses dan makna lebih di tonjolkan dalam penelitian kualitatif. Landasan teori dimanfaatkan sebagai pemandu agar fokus peneliti sesuai dengan fakta di lapangan. Metode pencarian data menggunakan metode kajian pustaka dimana kajian pustakan ini merupakan suatu kegiatan penelitian yang bertujuan melakukan kajian secara sungguh-sungguh tentang teori-teori dan konsepkonsep yang berkaitan dengan topik yang akan diteliti sebagai dasar dalam melangkah pada tahap penelitian selanjutnya. Metode riset yang sifatnya deskriptif,menggunakan analisis,mengacu pada data memanfaatkan teori yang sudah ada sebagai bahan pendukung,serta menghasilkan suatu teori.
Penelusuran literatur (Literature study) menjadi sarana utama untuk memperoleh informasi. Beberapa literature atau referensi berupa jurnal,buku teks,kamus,dokumen,internet serta berbagai artikel yang terkait dengan pariwisata dan ekonomi kreatif.

\section{HASIL DAN PEMBAHASAN}

Pariwisata sebagai kumpulan fenomena dan hubungan dengan yang tumbuh dari interaksi antar wisatawan (para pelancong), para pengusaha dengan pemerintah dan masyarakat tuan rumah kata pariwisata berasal dari bahasa jawa kuno, menurut kamus besar Bahasa Indonesia : kata pari berarti semua,segala,sekitar,sekeliling. Kata wisata berarti bepergian bersama-sama untuk memperluas pengetahuan,bersenang-senang dan sebagainya[19], [22].

Ekonomi kreatif merupakan sistem transaksi (supply and demand) yang memiliki pengertian lebih luas daripada industry kreatif. Menurut Wikipedia,ekonomi kreatif adalah sebuah konsep di era ekonomi baru yang mengintensifkan informasi dan kreativitas dengan mengandalkan ide dan pengetahuan dari sumber daya manusia sebagai faktor produksi yang utama. Konsep ini akan didukung dengan keberadaan industri kreatif yang menjadi pengejawantahannya[23], [24].

Kabupaten Garut yang dikenal sebagai "Swiss of Java" di karenakan secara kontur wilayah kota garut dikelilingi oleh nuansa pegunungan yang didukung oleh pola interaksi masyarakat yang ramah. Dengan kedua potensi yang dimiliki kabupaten garut tersebut dapat dijadikan sebagai modal yang sangat potensial untuk di kembangkan dan memajukan kawasan alam dan budaya Garut menjadi destinasi wisata yang "eksotis". Garut adalah kota di Indonesia yang sangat komplit mulai pariwisata pantai,pariwisata petualangan, pariwisata pegunungan, dan pariwisata artificial dapat di jadikan sebagai sumber pendapatan asli daerah (PAD) dari sektor pariwisata yang sangat menjanjikan. Sektor pariwisata Kabupaten Garut telah menjadi alternative destinasi wisata yang mudah di kunjungi bagi sebagian warga kota Bandung dan Jakarta setiap akhir pekannya. Adanya akses yang cepat di harapkan masyarakat kabupaten Garut, harus sadar wisata sebagai upaya memberikan keuntungan dan kesejahtraan dari sektor pariwisata yang berkelanjutan apabila dikelola dengan professional [25], [26]. Dari hasil penelitian bahwa yang menjadi faktor yang mempengaruhi jumlah kunjungan dan nilai 
Willingness to Pay diidentifikasi dengan regresi linier berganda.

Kabupaten Garut berpotensi untuk berkembang menjadi kota pariwisata. Sudah sejak dulu Garut menjadi tujuan wisata berkelas dunia. Saat itu tercatat tokoh-tokoh dunia seperti Rajan Thailand saat itu,Raja Leopold dari Belgia dan permaisurinya dari Swedia pernah datang ke Kabupaten Garut. Begitu pula dari kalangan selebritis kelas dunia seperti Charlie Chaplin yang datang dua kali dan konon memberikan julukan Garut "Swiss van Java"[27]. Ada beberapa hal yang membuat pariwisata layak di jadikan lokomotif pengembangan ekonomi kreatif Garut ke depan. Pertama,faktor sejarah atau masa lalu dimana Garut memiliki keunggulan Variatif. Kabupaten Garut terkenal dengan kelengkapan sekaligus keunikan daya tarik wisata yang dikenal dengan Gurilaps (GunungRimba-Laut-Pantai-Situ) yang jarang di temui didaerah lain. Bahkan penggiat pariwisata dan ekonomi kreatif garut, Franz Limiart mengatakan "Wisata di Garut yang paling siap memang wisata belanja". Pada tahun 1950-an Garut terkenal dengan sebutan kota Intan. Jarak yang tidak begitu jauh dari Bandung itu,menjadikan Garut cukup ramai dikunjungi oleh wisatawan domestic maupun wisatawan mancanegara. Hal ini terlihat dari padatnya Garut terutama pada akhir minggu atau musim libur anak sekolah. Pemerintah Garut membuat tagline "Ayo Wisata Jelajahi Garut" agar mudah mengidentifikasi dan membedakan Garut dengan kabupaten lain yang ada di Jawa Barat. Sehingga wisatawan yang datang ke Kabupaten Garut mendapatkan pengalaman yang berkesan dan sesuai dengan apa yang diharapkan oleh wisatawan sebelum datang ke kabupaten Garut[28], [29].

Berkembangnya wisata Garut mendorong masyarakat Garut menjadi lebih kreatif dalam menciptakan produk yang ditawarkan kepada wisatawan. Keberagaman produk dan jasa wisata yang ditawarkan menjadikan Garut sebagai salah satu kunjungan bagi para wisatawan untuk menikmati hasil cipta karya masyarakat Garut[30]. Sektor-sektor pariwisata pun mulai berkembang seakan menjadi trade mark baru dari Kabupaten Garut ini. sesuai dengan Vidi dan Misi Garut mewujudkan Garut sebagai daerah pariwisata disertai pelestarian dan pengembangan seni budaya lokal dan memberdayakan sistem ekonomi kerakyatan yang bertumpu pada potensi lokal dan mekanisme pasar. Banyaknya tempat objek wisata Garut seperti Cipanas, Situ Bagendit, Candi Cangkuang, Pantai Santolo merupakan tujuan wisata yang sering kali dikunjungi oleh wisatawan, hasil penelitian menunjukkan bahwa nilai ekonomi Pantai Santolo dengan metode Travel Cost adalah Rp. 114,26 Miliar pertahun untuk model linier dan Rp. 177,79 Miliar per tahun untuk model semi log seangkan hasil dari Metode Contingent Valuation adalah Rp. 3,65 Miliar per tahun. Faktor yang mempengaruhi jumlah kunjungan pada model liner ini adalah biaya perjalanan, pendapatan, dan pendidikan [31].

Kabupaten Garut dapat menciptakan kreasi dan inovasi yang menjadi produk unggulan indentitas Garut yang banyak di gemari oleh wisatawan, sehingga banyak wisatawan yang memilih untuk berkunjung ke daerah Garut dengan memilih produk sebagai oleholeh. Dengan adanya co-creation experience yang menjadi identitas Garut,maka wisatawan mendapat pengalaman dari berkunjung ke kabupaten Garut. Langkah pertama yang paling sederhana adalah mengembangkan wisata alam, misalnya dalam wisata pemandian air panas[32]. Garut ini memiliki wisata pemandian air panas populer. Untuk mengembangkan maka teori Expertiential marketing menjadi solusi tepat untuk mengembangkan wisata tersebut. Adanya peluang dalam bisnis industri kreatif yang didalamnya terdapat produk manufactur dan jasa pariwisata menyebabkan industri ini berada pada tingkat persaingan yang sangat tinggi. Selain itu semangat otonomi daerah yang berlangsung di Indonesia termasuk Kabupaten Garut mendorong beberapa kalangan untuk menggali dan mengangkat potensi daerah yang ada sebagai konstribusi pembangunan dan peningkatan citra kabupaten Garut.

\section{KESIMPULAN DAN SARAN}

Kabupaten Garut yang dikenal sebagai "Swiss of Java" di karenakan secara kontur wilayah kota garut dikelilingi oleh nuansa pegunungan yang didukung oleh pola interaksi masyarakat yang ramah. Dengan kedua potensi yang dimiliki kabupaten garut tersebut dapat dijadikan sebagai modal yang sangat potensial untuk di kembangkan dan memajukan kawasan alam dan budaya Garut menjadi destinasi wisata yang "eksotis". Berkembangnya wisata Garut mendorong masyarakat Garut menjadi lebih kreatif dalam menciptakan produk yang ditawarkan kepada wisatawan. Keberagaman produk dan jasa wisata yang ditawarkan menjadikan Garut sebagai salah satu kunjungan bagi para wisatawan untuk menikmati hasil cipta karya masyarakat Garut. Sektor-sektor pariwisata 
pun mulai berkembang seakan menjadi trade mark baru dari Kabupaten Garut ini. sesuai dengan Visi dan Misi Garut mewujudkan Garut sebagai daerah pariwisata disertai pelestarian dan pengembangan seni budaya lokal dan memberdayakan sistem ekonomi kreatif kerakyatan yang bertumpu pada potensi lokal dan mekanisme pasar. Garut merupakan salah satu wilayah yang sangat lengkap, mulai dari pariwisata pantai, pariwisata petualangan, pariwisata pegunungan, dan pariwisata artificial dapat di jadikan sebagai sumber pendapatan asli daerah (PAD) dari sektor pariwisata yang sangat menjanjikan. Kabupaten Garut merupakan salah satu daerah tujuan wisata di Jawa Barat karena banyak memiliki potensi wisata yang dapat menarik wisatawan untuk datang berkunjung. Banyaknya tempat objek wisata Garut seperti Cipanas, Situ Bagendit, Candi Cangkuang, Pantai Santolo merupakan tujuan wisata yang sering kali dikunjungi oleh wisatawan. Maka diperlukannya mengkaji potensi pariwisata di Kabupaten Garut untuk mewujudkan ekonomi kreatif.

\section{REFERENSI}

[1] Ramadhilla Maghfira Utami and Donald Crestofel Lantu, "Development of Competitivenes Model for Small - Medium," Indones. J. Bus. Adm., vol. 2, no. 11, pp. 13091318, 2013.

[2] R. A. Purnomo, Ekonomi Kreatif: Pilar Pembangunan Indonesia, Pertama., vol. 1. Surakarta: Ziyad Visi Media, 2016.

[3] A. D. Ananda, "PENGEMBANGAN USAHA MIKRO KECIL DAN MENENGAH (UMKM) BERBASIS EKONOMI KREATIF DI KOTA MALANG," 2017.

[4] G. A. F. Maulani and T. M. Sapril Mubarok, "Analisis Pengaruh Teknologi Informasi Pada Iklim Organisasi Dan Dampaknya Terhadap Komitmen Organisasi Perguruan Tinggi Swasta," J. Civ. Soc. Stud., vol. 4, no. 2, pp. 1224, 2020, doi: 10.31980/civicos.v4i2.912.

[5] R. Setiawan, "Faktor-Faktor yang Mempengaruhi Permintaan Jasa Pariwisata Pemandian Air Panas," Bus. Innov. Entrep. J., vol. 1, no. 1, pp. 53-61, 2019, [Online]. Available:

http://ejournals.fkwu.uniga.ac.id/index.php/BI EJ.

[6] D. I. Ekonomi, F. Ekonomi, and D. A. N. Manajemen, "Peranan sektor pariwisata terhadap perekonomian kabupaten garut dan potensi daya saingnya rina cipta novita," 2013.

[7] N. A. Sj, "Pelatihan Pemanfaatan Media Sosial Untuk Promosi Pariwisata Dan Potensi Kearifan Lokal Di Pantai Sayang Heualang Kab. Garut," J. Pengabdi. Kpd. Masy., vol. 2, no. 12, pp. 990-991, 2018, [Online]. Available: internal-pdf://249.1.110.30/20391-56178-1PB.pdf.

[8] E. Trihayuningtyas, W. Wulandari, Y. Adriani, and S. Sarasvati, "Media Sosial Sebagai Sarana Informasi Dan Promosi Pariwisata Bagi Generasi Z Di Kabupaten Garut," Tour. Sci. J., vol. 4, no. 1, p. 1, 2019, doi: 10.32659/tsj.v4i1.46.

[9] C. Ningsih, "Caria Ningsih : Sinergitas Industri Kreatif Berbasis Pariwisata dengan Strategi Pembangunan Industri Nasional Menuju Globalisasi SINERGITAS INDUSTRI KREATIF BERBASIS PARIWISATA DENGAN STRATEGI PEMBANGUNAN INDUSTRI NASIONAL MENUJU GLOBALISASI," Manaj. Resort Leis., vol. 11, no. 28, pp. 59-64, 2014.

[10] P. H. Adi, "HUBUNGAN ANTARA PERTUMBUHAN EKONOMI DAERAH, BELANJA PEMBANGUNAN DAN PENDAPATAN ASLI DAERAH," in SIMPOSIUM NASIONAL AKUNTANSI 9 PADANG, 2006, pp. 1-22.

[11] A. Wijanarko and I. Susila, "KEY SUCCESS FACTORS OF SMALL AND MEDIUM ENTREPRISES Aris Wijanarko ${ }^{1}$ dan Ihwan Susila $^{2}$ Abstrak Pendahuluan," in Prosiding Seminar Nasional Ekonomi dan Bisnis \& Call For Paper FEB UMSIDA, 2016, pp. 67-81.

[12] A. Romarina, "Economic Resilience Pada Industri Kreatif Gunamenghadapi Globalisasi Dalam Rangka Ketahanan Nasional," J. Ilmu Sos., vol. 15, no. 1, p. 35, 2016, doi: 10.14710/jis.15.1.2016.35-52.

[13] H. Saksono, "Ekonomi Kreatif: Talenta Baru Pemicu Daya Saing Daerah," J. Bina Praja, vol. 04, no. 02, pp. 93-104, 2012, doi: 10.21787/jbp.04.2012.93-104.

[14] N. A. Hamdani, "Building knowledge-creation for making business competition atmosphere in SMEs of Batik," Manag. Sci. Lett., vol. 8, pp. 667-676, 2018, doi: 10.5267/j.msl.2018.4.024.

[15] I. Tricahyadinata, "Kapabilitas Inovasi Usaha Kecil Dan Menengah Di Indonesia," Akuntabel, vol. 10, no. 1, pp. 1-18, 2013, doi: 10.29264/jakt.v10i1.49. 
[16] G. Li, A. N. N. Yong, and K. W. Ho, "Innovation, imitation and entrepreneurship," vol. 51, no. 2, pp. 147-173, 2006.

[17] R. Levickaite, "Four Approaches To the Creative Economy: General Overview," Business, Manag. Educ., vol. 9, no. 1, pp. 8192, 2011, doi: 10.3846/bme.2011.06.

[18] A. N. Fitriana, "Pengembangan Industri Kreatif Di Kota Batu (Studi Tentang Industri Kreatif Sektor Kerajinan Di Kota Batu)," J. Adm. Publik Mhs. Univ. Brawijaya, vol. 2, no. 2, pp. 281-286, 2014.

[19] P. S. Nugroho and M. Cahyadin, "Analisis Perkembangan Industri Kreatif di Indonesia," Fak. Ekon. Unviversitas Negeri Semarang, pp. 1-20, 2011.

[20] S. Moghavvemi, "Competitive Advantages Through It Innovation Adoption By Smes," vol. 7564, no. 1, pp. 24-39, 2012.

[21] N. A. Hamdani, G. A. F. Maulani, Tetep, and D. Supriyadi, "Human Capital to competitive advantage of micro industry coffee in Garut Regency through distinctive," in Advances in Business, Management and Entrepreneurship, London: Taylor \& Francis Group, LLC, 2020, pp. 983-987.

[22] K. Indahsari and H. Oktavianti, "Analisis Peran Pariwisata Pantai Camplong Terhadap Kesejahteraan Masyarakat Lokal," Media Trend Vol. 9 No. 2 Oktober 2014, hal. 181-195 Anal., vol. 9, no. 2, pp. 181-195, 2014.

[23] N. A. Hamdani, A. O. Herlianti, S. Nugraha, and A. Suparman, "Electronic - Word Of Mouth In Tourism 4 . 0 : Customer Review Of Online Travel Agent," no. 5, pp. 705-708, 2019, doi: 10.35940/ijeat.E1100.0585C19.

[24] I. Heliany, "Wonderful Digital Tourism Indonesia Dan Peran Revolusi Industri Dalam Menghadapi Era Ekonomi Digital 5.0," Destin. J. Hosp. dan Pariwisata, vol. 1, no. 1, pp. 2135, 2019, doi: 10.31334/jd.v1i1.551.

[25] A. P. P. Dini Turipanam Alamanda, Abdullah Ramdhan, "Preferensi Wisatawan Nusantara Terhadap Komponen Wisata Papandayan Menggunakan Analisis Konjoin," J. Manaj. Dan Kebijak. Publik, vol. 5, no. 52, p. 44, 2020, [Online]. Available: https://ejournal.undip.ac.id/index.php/gp/articl e/download/33282/17996.

[26] W. A. Susilawati Dini Turipanam; Maoludin, Agus; Ramdani, Risma Muhamad, "Evaluasi Kesadaran Wisatawatan Lokal Mengenai
Wisata Halal Pemandian Air Panas Garut," J. Pariwisata Indones., vol. 2, no. Vol 2 No 2 (2020): Jurnal ALTASIA (Edisi Khusus)Acceptance, pp. 199-207, 2020, [Online]. Available:

http://journal.uib.ac.id/index.php/altasia/article /view/563.

[27] F. Lestari, "Model Branding Tujuan Wisata Kabupaten Garut," Buku 2 Sos. dan Humanaiora, pp. 1-6, 2019.

[28] A. Suwirta, "Muatan Lokal Dan Sejarah Garut :," in Seminar Sejarah Lokal Kota Garut, 2001, vol. 0, pp. 1-5.

[29] Dinas Komunikasi dan Informatika Kabupaten Garut, "Sejarah Singkat Kabupaten Garut," www.garutkab.go.id, 2017. https://www.garutkab.go.id/page/sejarahsingkat.

[30] L. M. Lukman, "Garut Target Bentuk 60 Desa Wisata di 2020," Galamedia News, 2020. https://galamedia.pikiran-

rakyat.com/humaniora/pr-35552428/garut-

target-bentuk-60-desa-wisata-di-2020.

[31] Y. Haban, R. A. M. Koleangan, and G. M. V. Kawung, "Analisis Faktor-Faktor Yang Mempengaruhi Jumlah Kunjungan Dan Nilai Ekonomi Kebun Raya Bogor," J. Pembang. Ekon. Dan Keuang. Drh., vol. 19, no. 1, pp. 119, 2019, doi: 10.35794/jpekd.15775.19.1.2017.

[32] I. G. A. K. Giantari, "Kata Kunci :Strategi, Pengembangan, Objek Wisata, Air Panas, Marobo ABSTRACT," vol. 11, pp. 773-796, 2015. 